\title{
APPLICATION OF QUALITY AND PRODUCTIVITY IMPROVEMENT TOOLS IN A POTATO CHIPS PRODUCTION LINE
}

\author{
Ottilio João Tozin Junior ${ }^{1}$, Marcelo Carneiro Gonçalves ${ }^{2}$
}

\begin{abstract}
${ }^{1}$ Academico em Engenharia de Produção, no Centro Universitário Campos de Andrade - UNIANDRADE - PR. Brasil.
${ }^{2}$ Engenheiro de Produção, Mestre em Engenharia de Produção e Sistemas na Pontifícia Universidade Católica do Paraná PUCPR. Brasil.
\end{abstract}

Email: tozin.jr@hotmail.com, marcelo.ccbn@hotmail.com

Received: March $27^{\text {th }}, 2019$

Accepted: April 30 th, 2019

Published: June $30^{\text {th }}, 2019$

Copyright @2016 by authors and Institute of Technology Galileo of Amazon (ITEGAM).

This work is licensed under the Creative Commons Attribution International License (CC BY 4.0). https://creativecommons.org/lice $\underline{\text { nses/by/4.0/ }}$

\begin{abstract}
The objective of this study is to apply quality techniques with the purpose of proposing improvements for a production process of a potato chips production in a food industry in the region of Curitiba, Paraná state. Once the research universe was defined, the collection period began, characterized primarily by data collection, where it was divided into 2 periods: a first period reserved for checking the company's current performance, regarding production levels , income, compliance with goals and losses in the productive process; and a second period to verify the new performance of the plant after the implementation of the improvement plans proposed in this work, made possible by the use of the Cause and Effect Diagram, Brainstorming and 5W2H tools. With the implementation of the improvement plan, it was possible to observe an increase in the process incomes from $68.1 \%$ to $81.8 \%$ and a significant reduction in the level of losses in the production process of chips type chips.
\end{abstract}

Keywords: quality tools, continuous improvement, quality management, food industry.

\section{APLICAÇÃO DE FERRAMENTAS DE MELHORIA DE QUALIDADE E PRODUTIVIDADE EM UMA LINHA DE PRODUÇÃO DE BATATAS TIPO CHIPS \\ RESUMO}

O estudo tem por objetivo realizar a aplicação de técnicas de qualidade com a finalidade de propor melhorias para um processo produtivo de uma linha de produção de batatas do tipo chips, em uma empresa pertencente a uma indústria de alimentos na região de Curitiba, estado do Paraná. Definido o universo de pesquisa, iniciou-se o período de coleta, caracterizado primeiramente pelas atividades de captação e triagem de dados, onde foram divididos em 2 períodos: um primeiro período reservado para a checagem da performance atual da empresa, quanto aos níveis de produção, rendimentos, cumprimentos de metas e perdas no processo produtivo; e um segundo período que teve a finalidade de checar a nova performance da fábrica após a implantação dos planos de melhoria proposto nesse trabalho, viabilizados pelo uso das ferramentas de Diagrama de Causa e Efeito, Brainstorming e 5W2H. Com a implantação do plano de melhorias, foi possível observar um aumento no rendimento do processo que era de $68,1 \%$ para $81,8 \%$ e uma significativa redução no nível de perdas no processo de produção de batatas tipo chips.

Palavras-chave: ferramentas da qualidade, melhoria continua, gestão da qualidade, indústria de alimentos. 


\section{INTRODUÇÃO}

Economia globalizada, mercado competitivo, concorrência acirrada, impulsionou as organizações a desenvolver sistemas de melhor desempenho, redução de custos, melhor performance com planejamento e controle das manutenções de equipamentos e máquinas, tornando seus produtos e serviços competitivos no mercado interno e externo.

Neste contexto, surgiu a necessidade de as empresas implantarem sistemas e modelos de produção para minimizar a probabilidade de falhas no processo, buscando melhor produtividade, evitando falhas e perdas desnecessárias, permitindo que os equipamentos e máquinas estejam sempre disponíveis a produzir, atingindo níveis satisfatórios de custos, flexibilidade, tempo, inovação e de qualidade [1].

No âmbito nacional, para que as empresas sejam capazes de enfrentar a concorrência globalizada, é fundamental o entendimento entre os fatores de produção vigentes no país e as diferenças econômicas entre as nações. Atualmente, em um ambiente de constantes mudanças, há um esforço necessário nas fábricas para que as mesmas sejam eficazes nos seus sistemas de produção e capazes de produzir a baixos custos [2].

Nas primeiras décadas da Revolução Industrial, a produção era predominantemente de forma artesanal e o aumento da produtividade era obtido com a produção mecanizada.

Isso era suficiente para que as empresas ficassem em uma posição confortável em relação ao atendimento da demanda.

A partir da segunda década do século XX, com o advento da administração cientifica de Taylor e da linha de produção de Ford, houve mudança na lógica de produção, ocorrendo melhorias significativas na produtividade industrial em função das especializações do trabalho e da padronização das peças e dos produtos.

Isso foi conseguido, pois a demanda do mercado era superior à produção. Porém, a medida que a oferta de produtos começou a superar a procura, as restrições da competição determinam que as ineficiências tenham que ser reduzidas drasticamente, para obter o ciclo no mercado a empresa precisa produzir de forma eficiente, monitorando o desempenho de suas atividades e rendimento de seus equipamentos [3].

As décadas de 50 e 60 classificam-se com a estabilidade e crescimento. A partir das décadas de 80 e 90 as mudanças nos processos foram de maior evidencias nas organizações. Áreas de Marketing, Sistema de Informação e gerenciamento de Recursos Humanos passam por transformação na sua filosofia gerencial.

A imprescindível busca por redução de desperdícios e custos foi fator determinante para criação de equipes multidisciplinares e trabalho em equipe.

Empregando técnicas de produção enxuta e limpa, com trabalho em conjunto e utilizando metodologias de análise e controle foi possível identificar e tratar problemas de diferentes complexibilidade, buscando soluções criativas a serem implantadas [4].

No entanto a evolução não parou o seu desenvolvimento, que enfrenta em cada fase maiores desafios, sejam eles de processos tecnológicos, atendimento a requisitos específicos, ou até mesmo a situações econômicas, das quais os processos precisam ser mais enxutos, evitando desperdícios e reduzindo custos por má qualidade. E para sustentar este sistema de produção se faz necessária a aplicação contínua da qualidade, onde é fundamental a participação dos funcionários na sua elaboração, implantação e execução.

Mais afinal o que é qualidade? O termo qualidade há muito tempo já faz parte do vocabulário de muitas pessoas, mas como defini-lo de forma a atingir toda a dimensão do seu significado? A qualidade envolve muitos aspectos simultaneamente e sofre alterações conceituais ao longo do tempo [5]. Quando direcionada para gestão da qualidade, o conceito genérico de qualidade assimila novas nuances todas relacionadas ao desempenho das operações desenvolvidas nas organizações. Esse conceito genérico é proposto diferentemente por diversos autores estudiosos da qualidade e baseia-se comumente na proposição de que a qualidade é o resultado do que o cliente quer e como ele julga ser, constituindose em diretriz na busca da excelência pelas organizações [6]. A gestão da qualidade é uma abordagem adotada e o conjunto de práticas utilizadas pela empresa para se obter, de forma eficiente e eficaz. A qualidade não pode estar separada das ferramentas estatísticas e logicas básicas usadas no controle, melhoria e planejamento da qualidade. Estas ferramentas foram largamente difundidas, porque fazem com que as pessoas envolvidas no controle de qualidade vejam através de seus dados e compreendam a razão dos problemas, desta forma sendo possível determinar soluções para eliminá-los e, consequentemente, melhorar a eficiência dos processos.

Uma maneira eficaz de se aumentar a eficiência dos mais diversos processos é a utilização das ferramentas da qualidade. Através do auxílio dessas ferramentas, o gestor é capaz de controlar melhor o(s) processo(s) sob sua responsabilidade, pois elas o ajudam em pontos cruciais da gerência, como a busca da causa dos problemas e o grau de importância destes.

A importância da gestão da qualidade na indústria alimentícia levou ao desenvolvimento das teorias e práticas da Gestão da Qualidade Total. Bastante conhecida nos países ocidentais como TQM, (da sigla em inglês, Total Quality Management, traduzindo, Gestão da Qualidade Total), essa filosofia de gestão é baseada no princípio de melhoria contínua de produtos e processos visando satisfazer as expectativas dos clientes com relação à qualidade, custos, entrega e serviços. A melhoria contínua adota uma abordagem de melhoramento incremental, ou seja, de melhoramentos contínuos. Nessa abordagem, a continuidade do processo de melhoria é mais importante do que o tamanho de cada passo de melhoria [7].

Inicialmente, foram apresentados alguns termos e conceitos referentes ao tema em questão. Em seguida, a pesquisa abordou quase que exclusivamente o Sistema de Gestão da Qualidade, apresentando suas principais ferramentas utilizadas na indústria alimentícia. Com o objetivo de facilitar o controle de processos no sistema de produção para melhoria da qualidade, foram desenvolvidas as ferramentas da qualidade, que facilitam a aplicação de conceitos, coleta e apresentação de dados. As ferramentas da qualidade são métodos utilizados para a melhoria de processos e solução de problemas em qualidade. O uso dessas ferramentas tem como objetivo, a clareza no trabalho e principalmente a tomada de decisão com base em fatos e dados, em vez de opiniões. As ferramentas são utilizadas na indústria por ter a grande capacidade e consciência em remover as causas dos problemas, onde se obtém uma maior produtividade e a redução de perdas, essas ferramentas auxiliam na resolução de problemas utilizando técnicas específicas e gráficas que produzem melhores resultados do que os processos de procura não estruturados [8].

Com um bom conhecimento do mercado as empresas se habituam na busca de atender aos requisitos do cliente e, consequentemente, melhorar a sua imagem externa. $\mathrm{O}$ alicerce para que os novos projetos de produtos e serviços sejam colocados em prática está no sistema de qualidade que procura alinhar o que foi planejado com o executável. A distância entre o planejamento e a execução pode ser menor ou maior em razão da estrutura física onde os processos são executados, layout, pessoas, ferramentas, equipamentos, fluxo de comunicação, ambiente de trabalho, liderança, padronização de processos, indicadores de medidas; 
enfim, tudo que é necessário para a implantação das ações voltadas para a qualidade [9].

O objetivo desse artigo é analisar os efeitos do controle da qualidade aplicado ao processamento de batatas, utilizando-se de ferramentas de qualidade, afim de verificar as suas contribuições para a melhoria do processo produtivo e redução de perdas de matéria prima.

Esse artigo está estruturado da seguinte forma: A seção 1 contempla a introdução a qual é contextualizado o problema; A seção 2 apresenta a metodologia de pesquisa; A seção 3 apresenta a revisão bibliográfica pertinente à pesquisa; A seção 4 contempla os resultados; A seção 5 apresenta as considerações finais da pesquisa de forma sucinta e coerente e por fim são citadas as referências.

\section{REFERENCIAL TEÓRICO}

\section{II.1 CONCEITO DE QUALIDADE NO CONTEXTO ALIMENTÍCIO}

Entende-se que um produto ou serviço é de qualidade se além de atender as características técnicas e requerimentos que deles se esperam, adequando ao uso e vierem a satisfazer os clientes/consumidores que lhes usam ou consomem [12], portanto, para ter qualidade é preciso satisfazer aos clientes ou consumidores, além de atender suas características esperadas.

O público consumidor da indústria de alimentos está cada vez mais exigente. Neste contexto, o controle da qualidade se faz essencial para a satisfação dos clientes. Além disso, proporciona a redução dos erros durante o processo de produção. Então, pode-se dizer que o controle da qualidade na indústria de alimentos é uma adequação sanitária do produto visto que erros de processos podem ocasionar contaminação por agentes químicos, físicos ou biológicos [13].

A qualidade é percebida diferentemente pelo consumidor e pela indústria. Aos olhos do consumidor características como: aspecto visual, sabor, odor e até a composição nutricional são fundamentais. Assim o controle de qualidade garante a manutenção do mercado consumidor e abre novas possibilidades de negócios.

$\mathrm{O}$ controle de qualidade permite a identificação de áreas problemas e identificação de prioridades; possibilidade de avaliação de investimentos de capital; justificativa para investimentos em atividades de prevenção e melhoria da qualidade; medição de desempenho; e por fim, uma maneira de alcançar melhoria no retorno de investimentos e aumento de vendas quando os custos são reduzidos [14].

\section{II.2 FERRAMENTAS DE QUALIDADE}

\section{II.2.1 DIAGRAMA DE CAUSA EFEITO}

Também conhecido como espinha de peixe ou diagrama de Ishikawa, o diagrama é usado para mostrar relação entre causas e efeitos de um determinado problema a ser investigado. Neste diagrama são investigados os aspectos: método, matéria prima, mão-de-obra, máquina, medida e meio ambiente. Devido a estes fatores, também é conhecido por $6 \mathrm{M}$. Este método permite estruturar ordenadamente as causas de um problema, seus efeitos sobre processos e a qualidade dos produtos [15].

Geralmente é elaborado de um brainstorming. No $\mathrm{M}$ de método são detalhados os aspectos e informações relacionadas ao sistema de trabalho, os procedimentos, técnicas e rotinas utilizadas. No $\mathrm{M}$ de medida é destacado como é medido o processo e seu formato, como calibrações e aferições dos instrumentos de medição. No M de-mão-de-obra ocorrem as especificações relacionadas os aspectos das máquinas envolvidas. No $\mathrm{M}$ do meio ambiente são especificadas as características físicas do ambiente de trabalho, como temperatura, ruído e iluminação. No $\mathrm{M}$ de matéria prima são abordadas as características dos insumos que compõem o processo. O efeito contém os indicados de qualidade ou o problema para o estudo. $\mathrm{E}$ no $\mathrm{M}$ de máquinas são abordadas as características de depreciação, manutenções e falhas.

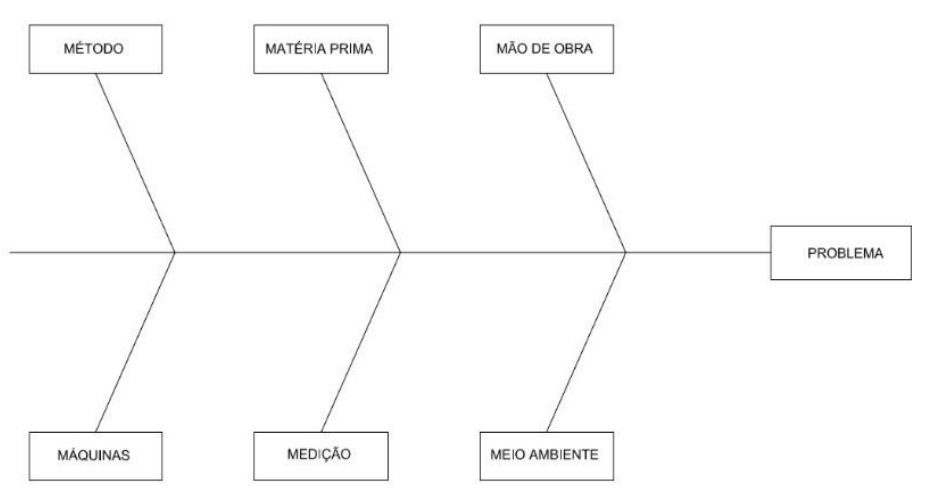

Figura 1: Diagrama de Ishikawa Fonte: Autor, 2018.

\section{II.2.2 BRAINSTORMING}

Brainstorming é uma rodada de ideias, destinada à busca de sugestões através do trabalho de grupo para inferências sobre causas e efeitos de problemas e sobre tomada de decisão [16], também conhecido como "chuva de ideias" pode ser conduzido de duas maneiras [17];

- Brainstorming estruturado: são feitas rodadas sequenciais, nas quais cada pessoa deve contribuir com uma ideia ou "passar" até a próxima rodada. Sua vantagem é dar chance de participação para todos;

- Brainstorming não estruturado: os membros do grupo podem dar ideias livremente. Sua vantagem é criar uma atmosfera descontraída e facilitar o desencadeamento de ideias, mas há o risco de a participação ser monopolizada pelas pessoas mais desinibidas.

Utilizando qualquer uma destas maneiras, é importante lembrar que nenhuma das ideias deve ser recriminada.

\section{II.2.3 TÉCNICA 5W2H}

Consiste de um check list fácil e prático com atividades a serem executadas para qualquer situação desejada. É um mapeamento de atividades no qual são estabelecidas as informações mais importantes e significativas sobre qualquer projeto, processo ou atividade [15].

Para cada meta ou atividade a ser executada ocorre o estabelecimento das ações a serem realizadas, bem como o planejamento destas ações através do estabelecimento da prazos, nomeação de responsáveis e a forma como as ações serão desenvolvidas, na forma de um cronograma [18].

É considerada uma ferramenta básica da qualidade para elaboração de plano de ação englobando os envolvidos na solução de um determinado problema, levando em consideração as iniciais, em inglês, das sete palavras que dão origem ao $5 \mathrm{~W} 2 \mathrm{H}$.

Segue abaixo o significado de cada letra.

- What? O quê? - Etapas

- Who? Quem? - Responsabilidade

- Where? Onde? - Local 
- When? Quando? - Tempo

- Why? Por quê? - Justificativa

- How? Como? - Metodo

- How Much? Quanto custará? - Valores

\section{METOLOGIA DA PESQUISA}

Este estudo classifica os dados coletados como qualitativo e quantitativo, segundo Kauark, Manhães e Medeiros [10] comenta que a pesquisa qualitativa foca no processo produtivo, $o$ pesquisador torna-se peça fundamental no ambiente para coleta dos dados. Para [11], comenta que pesquisas quantitativas na maioria dos casos as coletas de dados são realizadas mediante observação e análise de registros de documentos.

Este estudo foi realizado por meio de observação individual direta, nas quais os dados foram coletados ao longo do processo de produção, onde foi possível, com auxílio de ferramentas da qualidade, identificar possíveis variações no processo de frituras de batata chips.

As etapas para a construção deste trabalho estão organizados da seguinte forma: inicialmente foi realizado um levantamento da bibliografia sobre os principais conceitos a respeito das ferramentas de qualidade; em seguida, foi realizado o levantamento dos dados na empresa divididos em 2 períodos, que serão descritos a seguir; na sequência, foi aplicado as ferramentas da qualidade, a saber: Diagrama de Causa e Efeito, Brainstorming e $5 \mathrm{~h} 2 \mathrm{H}$ sobre o caso estudado, com a finalidade de analisar e propor um plano de ação para a empresa e alcance de seus objetivos organizacionais.

\section{III.1 A EMPRESA}

O presente trabalho foi realizado em uma indústria de alimentos de médio porte, situada na região metropolitana de Curitiba, contando com um parque industrial de 15.000,00 m2, com aproximadamente 500 funcionários trabalhando em 2 turnos. A empresa iniciou suas atividades em 2008, no segmento de snacks (salgadinhos). A empresa aparece entre as mais importantes no cenário nacional, produz 11 tipos de produtos. Seu principal produto é a batata frita tipo chips.

O processamento da batata na forma de chips é um processo simples, porém requer matéria prima de excelente qualidade. Para atingir essa excelência em qualidade, a empresa investe em tecnologia de ponta colocada à disposição do produtor.

\section{III.2 IDENTIFICAÇÃO DO PROBLEMA}

Foi realizado um levantamento das perdas de batata frita tipo chips em 2 momentos distintos que será designado como: períodos, a saber: agosto de 2017 a dezembro de 2018 ( $1^{\circ}$ período) e julho de 2018 a outubro de 2018 ( $2^{\circ}$ período). A justificativa dessa divisão, ocorreu devido a necessidade de mensurar a performance da empresa antes e depois da aplicação do plano de melhorias proposto neste estudo.

A coleta iniciou-se pela observação e registro das etapas do processo produtivo na fábrica com a finalidade de identificar os principais fatores que implicam na variação e eficiência da produtividade no processo produtivo.

Com isso, foi identificado que a empresa não consegue cumprir o alcance de metas estabelecidos nos objetivos organizacionais, onde a produção encontra-se sempre abaixo da meta a ser atingida nos dois períodos de análise.

Além disso, no processo produtivo existe uma alta frequência de diferenciação dos tamanhos das batatas do tipo chips, devido ao formato dos cortes e do fatiamento das mesmas, o que ocasiona um excesso na perda de matéria prima.

\section{RESULTADOS}

\section{IV.3 APRESENTAÇÃO DOS RESULTADOS LEVANTADOS NO PRIMEIRO PERÍODO}

Na tabela 1, os valores apresentados na primeira linha referem-se ao consumo previsto de batatas considerados através de dados históricos do processo, a segunda linha referem-se a valores determinados pela gerencia da fábrica como meta de produção, a terceira, refere-se a produção efetiva de batata que ocorreu, a quarta linha refere-se a perda que ocorreu de batatas ao longo do período, a quinta linha refere-se a valores de rendimentos atingidos pelo processo e a sexta linha referem-se a valores fixos de metas de rendimentos estabelecidas pela empresa.

Tabela 1 - Dados obtidos no primeiro período.

\begin{tabular}{|cccccc|}
\hline \multicolumn{7}{c}{ Consumo mensal de batatas } \\
\hline & Ago/17 & Set/17 & Out/17 & Nov/17 & Dez/17 \\
\hline $\begin{array}{c}\text { Consumo Previsto de } \\
\text { batata (ton) }\end{array}$ & 1000 & 1000 & 1000 & 1000 & 1000 \\
\hline $\begin{array}{c}\text { Meta de batata frita } \\
\text { entregue (ton) }\end{array}$ & 850 & 850 & 850 & 850 & 850 \\
\hline $\begin{array}{c}\text { Batata frita entregue no } \\
\text { período (ton) }\end{array}$ & 622 & 685 & 710 & 691 & 698 \\
\hline $\begin{array}{c}\text { Perdas de batata no } \\
\text { processo (ton) }\end{array}$ & 228 & 165 & 140 & 159 & 152 \\
\hline $\begin{array}{c}\text { Rendimento do processo } \\
(\%)\end{array}$ & $62,2 \%$ & $68,5 \%$ & $71 \%$ & $69,1 \%$ & $69,8 \%$ \\
\hline $\begin{array}{c}\text { Meta estabelecida de } \\
\text { rendimento do processo } \\
(\%)\end{array}$ & $85 \%$ & $85 \%$ & $85 \%$ & $85 \%$ & $85 \%$ \\
\hline
\end{tabular}

Fonte: Autores, (2018).

A Figura 1 mostra os consumos apresentados na tabela 1, que se refere ao consumo de batatas no primeiro período analisado neste trabalho, compreendendo de agosto de 2017 a dezembro de 2017. Neste gráfico apresenta-se o consumo previsto, a meta, o total entregue e o quantitativo de perdas de batatas fritas tipo chips (em toneladas) no primeiro período. Pode-se destacar que neste período em nenhum momento a produção de batatas atingiu a meta estabelecida pela empresa e o quantitativo de perdas de batatas estão presentes ao longo de todo o período analisado.

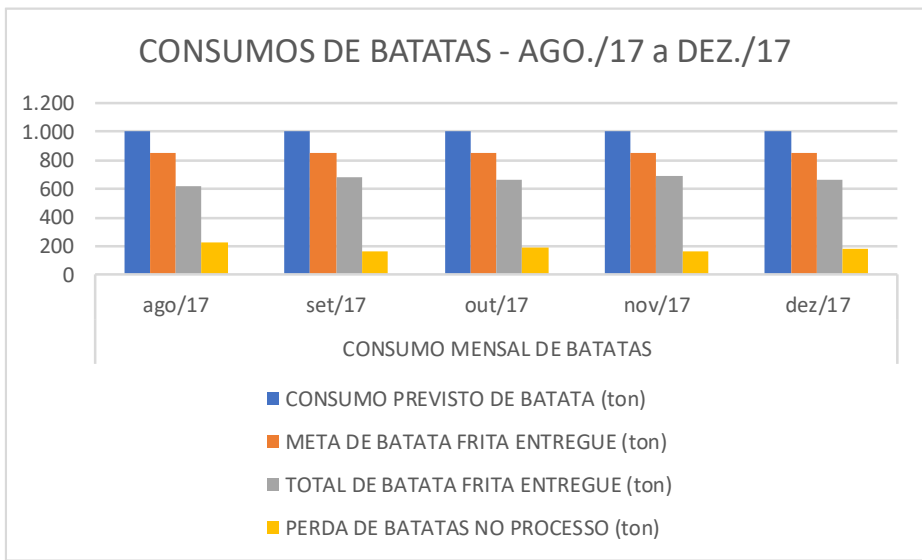

Figura 1 - consumos no primeiro período.

Fonte: Autores, (2018).

De acordo com a tabela 1, a Figura 2 apresenta um comparativo entre as metas de rendimento estabelecidos pela alta administração da empresa e o rendimento efetivamente alcançado 
no primeiro período. É possível notar neste gráfico que durante o levantamento de dados coletados no primeiro período de analise, em nenhum momento a empresa atingiu as metas estabelecidas, ou seja, a produção esteve sempre aquém do objetivo em cada mês.

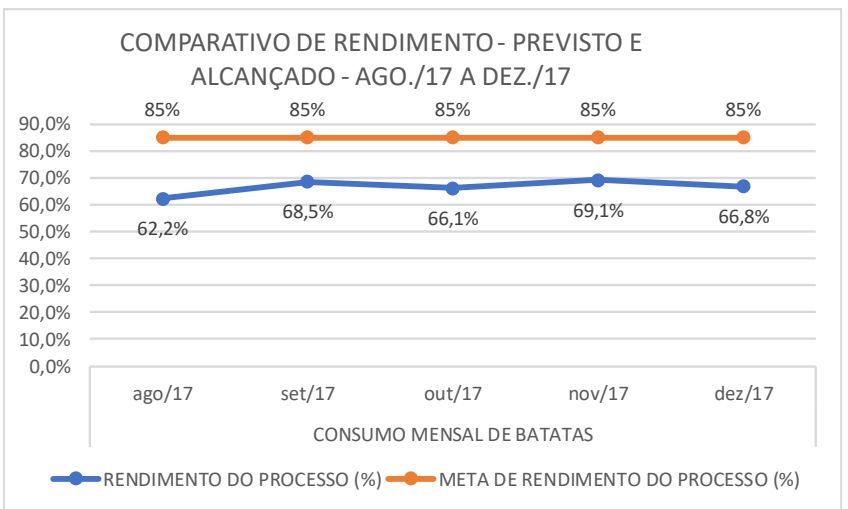

Figura 2 - comparativo de rendimentos.

Fonte: Autores, (2018).

\section{IV.4 APLICAÇÃO DAS FERRAMENTAS DE QUALIDADE}

Após análise dos dados levantados e apresentados na tabela 1 , foi realizado um planejamento para identificar a causa raiz das perdas de matéria prima no processo produtivo. $\mathrm{O}$ projeto teve a participação de várias áreas envolvidas no processo produtivo, como: operadores, engenharia de processo, engenharia de projetos, qualidade e manutenção.

O planejamento consiste na análise dos dados levantados e aplicação das ferramentas da qualidade para solucionar os problemas e reduzir as perdas no processo produtivo.

\section{IV.1 DIAGRAMA DE CAUSA E EFEITO}

$\mathrm{Na}$ análise do diagrama de causa efeito foram identificadas as possíveis causas em relação a matéria prima e máquinas, conforme apresentado na figura 3 .

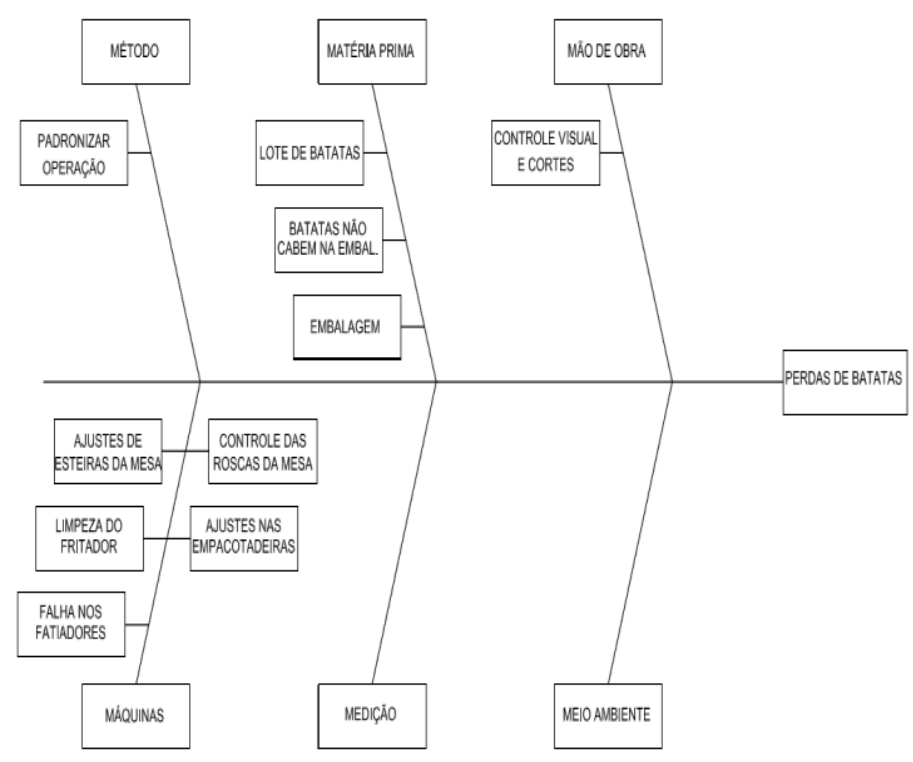

Figura 3 - Diagrama de Causa Efeito.

Fonte: Autores, (2018).

\section{IV.4.2 BRAINSTORMING}

Após análise do diagrama de causa e efeito foi realizado um questionário com todos os envolvidos procurando encontrar as evidencias dos problemas, identificando as causas e encontrando uma solução para minimizar as perdas processo de produção conforme Quadro 1.

\section{Quadro 1 - Questionário de Brainstorming.}

\begin{tabular}{|c|c|c|}
\hline Evidências & Causas Prováveis & $\begin{array}{c}\text { Soluções } \\
\text { Encontadas }\end{array}$ \\
\hline $\begin{array}{l}\text { Lote de batatas } \\
\text { com dimensões } \\
\text { heterogeneas }\end{array}$ & $\begin{array}{c}\text { Controle de amostragem de } \\
\text { batatas, é realizado em dois } \\
\text { pontos da carga }\end{array}$ & $\begin{array}{c}\text { Aumentar a } \\
\text { amostragem do lote } \\
\text { em } 6 \text { pontos } \\
\text { distintos da carga }\end{array}$ \\
\hline $\begin{array}{c}\text { Ajuste manual na } \\
\text { esteira da entrada } \\
\text { da mesa de controle } \\
\text { e inspeção }\end{array}$ & $\begin{array}{l}\text { Como foi verificado que o } \\
\text { controle da amostragem é } \\
\text { reduzido, não é possivel realizar } \\
\text { o ajuste correto da esteira de } \\
\text { entrada da mesa }\end{array}$ & $\begin{array}{c}\text { Com mais pontos } \\
\text { de coleta na carga } \\
\text { esse problema será } \\
\text { reduzido }\end{array}$ \\
\hline $\begin{array}{l}\text { Corte manual das } \\
\text { batatas na mesa de } \\
\text { inspeção e controle }\end{array}$ & $\begin{array}{l}\text { Controle de tamanhos e cortes é } \\
\text { realizado de forma visual e com } \\
\text { um lote de batatas heterogêneo } \\
\text { um controle mais efetivo fica } \\
\text { comprometido, deixando muitas } \\
\text { batatas fora das dimensões } \\
\text { passarem pelo corte manual }\end{array}$ & $\begin{array}{l}\text { Realizar estudo de } \\
\text { mercado e com } \\
\text { outras plantas da } \\
\text { empresa, para } \\
\text { aquisição de um } \\
\text { equipamento de } \\
\text { corte e seleção } \\
\text { automático de } \\
\text { batatas }\end{array}$ \\
\hline $\begin{array}{l}\text { Batatas apresentam } \\
\text { falhas no processo } \\
\text { de fatiamento }\end{array}$ & $\begin{array}{c}\text { Conforme descrito no item } \\
\text { anterior, varias batatas grandes } \\
\text { passam pela mesa sem receber o } \\
\text { corte, e acabam chegando aos } \\
\text { fatiadores, que não conseguem } \\
\text { fatiar as batatas em sua } \\
\text { totalidade, causando um } \\
\text { esfarelamento de } 30 \% \text { em média } \\
\text { no fatiamento }\end{array}$ & $\begin{array}{l}\text { Com aquisição de } \\
\text { um equipamento } \\
\text { esse problema será } \\
\text { reduzido }\end{array}$ \\
\hline $\begin{array}{l}\text { Acúmulo de } \\
\text { "scraps", no } \\
\text { fritador }\end{array}$ & $\begin{array}{l}\text { Os 'scraps'" que são os farelos } \\
\text { provenientes dos fatiadores, não } \\
\text { conseguem flutuar no fritador e } \\
\text { ficam depositados no fundo do } \\
\text { mesmo, ocasioanando uma } \\
\text { limpeza com maior frequência e } \\
\text { paradas no processo produtivo }\end{array}$ & $\begin{array}{l}\text { Com aquisição de } \\
\text { um equipamento } \\
\text { esse problema sera } \\
\text { reduzido }\end{array}$ \\
\hline $\begin{array}{c}\text { Batatas não cabem } \\
\text { dentro da } \\
\text { embalagem }\end{array}$ & $\begin{array}{l}\text { Com as batatas fatiadas fora dos } \\
\text { padrões, as mesmas não cabem } \\
\text { dentro da embalagem, e no } \\
\text { processo de selagem as bolsas } \\
\text { não recebem a solda na sua } \\
\text { totalidade, deixando a bolsa mal } \\
\text { fechada, ocasionando problemas } \\
\text { com a qualidade final do } \\
\text { produto, gerando reclamações } \\
\text { do consumidor }\end{array}$ & $\begin{array}{l}\text { Com aquisição de } \\
\text { um equipamento } \\
\text { esse problema sera } \\
\text { reduzido }\end{array}$ \\
\hline $\begin{array}{c}\text { Máquinas de } \\
\text { empacotar com } \\
\text { paradas frequentes } \\
\text { para ajustes }\end{array}$ & $\begin{array}{c}\text { No processo de selagem, quando } \\
\text { a solda é executada, fica } \\
\text { acumulado nos mordentes restos } \\
\text { de batatas, ocasionando } \\
\text { desalinhamento dos mesmos, e } \\
\text { isso ocasiona várias paradas } \\
\text { para limpeza e alinhamento. }\end{array}$ & $\begin{array}{c}\text { Consultar } \\
\text { fabricante do } \\
\text { equipamento para } \\
\text { atualização de } \\
\text { software, realizar } \\
\text { upgrade nos } \\
\text { equipamentos, e } \\
\text { realizar plano de } \\
\text { manutenção } \\
\text { corretiva }\end{array}$ \\
\hline $\begin{array}{l}\text { Padronização da } \\
\text { operação no } \\
\text { processo produtivo }\end{array}$ & $\begin{array}{c}\text { Procedimentos de operações de } \\
\text { máquinas apresentando falhas } \\
\text { nas revisões, dificuldade do } \\
\text { operador em encontrar } \\
\text { documentos na rede } \\
\text { coorporativa }\end{array}$ & $\begin{array}{c}\text { Revisar os } \\
\text { procedimentos e } \\
\text { coloca-los de fácil } \\
\text { verificação em todo } \\
\text { o processo } \\
\text { produtivo }\end{array}$ \\
\hline
\end{tabular}

Fonte: Autores, (2018). 
Após as análises das informações observou-se que a causa raiz das perdas de batatas no processo de produção estão concentradas na matéria-prima e nos equipamentos.

\section{IV.3 PLANO DE AÇÃO}

Após identificação da causa raiz do problema, foi elaborado um plano de ação para resolver e neutralizar os motivos que causam as perdas mencionadas.
Desta forma foi elaborado um plano de ação utilizando a metodologia 5W2H, conforme Quadro 2, o objetivo deste plano é colocar em prática medidas para minimizar as perdas de batatas e embalagens.

Quadro 2 - apresentação do 5W2H.

\begin{tabular}{|c|c|c|c|c|c|c|}
\hline \multicolumn{7}{|c|}{$5 \mathrm{~W} 2 \mathrm{H}$} \\
\hline O QUE & QUEM & QUANDO & ONDE & PORQUE & COMO & QUANTO \\
\hline $\begin{array}{l}\text { Controle do } \\
\text { recebimento das } \\
\text { batatas na fábrica }\end{array}$ & $\begin{array}{c}\text { setor da } \\
\text { qualidade }\end{array}$ & $\begin{array}{c}\text { a cada } \\
\text { descarregamento } \\
\text { de batatas }\end{array}$ & $\begin{array}{c}\text { setor de } \\
\text { descarregamento }\end{array}$ & $\begin{array}{c}\text { mapeamento do lote, com controle } \\
\text { de tamanhos de batatas }\end{array}$ & $\begin{array}{c}\text { executar amostragem na } \\
\text { carga, aumentando o ponto de } \\
\text { coletas na carga, e atribuir um } \\
\text { indicador para controle do } \\
\text { recebimento da carga }\end{array}$ & sem ônus \\
\hline $\begin{array}{l}\text { Redução do tamanho } \\
\text { das batatas }\end{array}$ & $\begin{array}{l}\text { operação, } \\
\text { engenharia de } \\
\text { processos e } \\
\text { engenharia de } \\
\text { projetos }\end{array}$ & mai/18 & $\begin{array}{c}\text { área de inspeção } \\
\text { e seleção }\end{array}$ & $\begin{array}{c}\text { para evitar que batatas grandes } \\
\text { sejam enviadas aos fatiadores } \\
\text { gerando desperdicio no corte, } \\
\text { ocasionando acúmulo de "scraps" } \\
\text { no fritador, evitando paradas para } \\
\text { limpeza, e tambem evitando que } \\
\text { batatas sejam fatiadas fora da } \\
\text { especificação, ocasionando } \\
\text { problemas no empacotamento }\end{array}$ & $\begin{array}{l}\text { adquirir e instalar } \\
\text { equipamento de corte } \\
\text { automático de batatas }\end{array}$ & $\mathrm{R} \$ 1.500 .000,00$ \\
\hline $\begin{array}{l}\text { Ajustes nas máquinas } \\
\text { de empacotamento }\end{array}$ & $\begin{array}{c}\text { manutenção e } \\
\text { setor de } \\
\text { qualidade }\end{array}$ & mai/18 & empacotamento & $\begin{array}{c}\text { para evitar constantes ajustes nas } \\
\text { máquinas, causando mau formação } \\
\text { de bolsas, e desalinhamento, } \\
\text { deixando o produto fora da } \\
\text { especificação }\end{array}$ & $\begin{array}{l}\text { ajustes técnicos nas máquinas, } \\
\text { substituição de peças } \\
\text { desgastadas, atualização de } \\
\text { software, e desenvolvimento } \\
\text { de padrões de trabalho }\end{array}$ & $\mathrm{R} \$ 100.000,00$ \\
\hline
\end{tabular}

Fonte: Autores, (2018).

De acordo com o plano de ação, a alta direção, juntamente com a equipe de engenharia de processos e projetos, optou por fazer um estudo para a compra de um equipamento para seleção e corte automático de batatas.

Após a finalização do processo de pesquisa de mercado e definição do fornecedor, a compra do equipamento foi finalizada.

O processo de escolha até a instalação do equipamento teve duração de 6 meses.

Para instalação do equipamento foi necessário executar algumas adaptações no layout, como execução de estrutura para o equipamento e ajustes de esteiras de transporte, após execução de todas as adaptações na linha de produção o equipamento foi instalado, iniciando as operações em junho/2018.

Após o início do equipamento, a equipe de engenharia, qualidade e manutenção realizou um acompanhamento de funcionamento do equipamento e realizou um levantamento de informações para análise de melhoria da performance da linha de produção e controle da causa raiz.

\section{IV.4 APRESENTAÇÃO DOS RESULTADOS LEVANTADOS NO SEGUNDO PERÍODO}

A tabela 2, da mesma forma como foi apresentada para a tabela 1, os valores apresentados na primeira linha referem-se ao consumo previsto de batatas considerados através de dados históricos do processo, a segunda linha referem-se a valores determinados pela gerencia da fábrica como meta de produção, a terceira, refere-se a produção efetiva de batata que ocorreu, a quarta linha refere-se a perda que ocorreu de batatas ao longo do período, a quinta linha refere-se a valores de rendimentos atingidos pelo processo e a sexta linha referem-se a valores fixos de metas de rendimentos estabelecidas pela empresa.

Tabela 2 - Dados obtidos no segundo período.

\begin{tabular}{|cccccc|}
\hline \multicolumn{7}{|c|}{ Consumo mensal de batatas } \\
\hline $\begin{array}{c}\text { Consumo Previsto de } \\
\text { batata (ton) }\end{array}$ & 1000 & 1000 & 1000 & 1000 & 1000 \\
\hline $\begin{array}{c}\text { Meta de batata frita } \\
\text { entregue (ton) }\end{array}$ & 850 & 850 & 850 & 850 & 850 \\
\hline $\begin{array}{c}\text { Batata frita entregue no } \\
\text { período (ton) }\end{array}$ & 768 & 808 & 825 & 842 & 849 \\
\hline $\begin{array}{c}\text { Perdas de batata no } \\
\text { processo (ton) }\end{array}$ & 232 & 192 & 175 & 158 & 151 \\
\hline $\begin{array}{c}\text { Rendimento do processo } \\
(\%)\end{array}$ & $76,8 \%$ & $80,8 \%$ & $82,5 \%$ & $84,2 \%$ & $84,9 \%$ \\
\hline $\begin{array}{c}\text { Meta estabelecida do } \\
\text { processo (\%) }\end{array}$ & $85 \%$ & $85 \%$ & $85 \%$ & $85 \%$ & $85 \%$ \\
\hline
\end{tabular}

Fonte: Autores, (2018).

A Figura 4 ilustra os dados apresentados na tabela 2, que se refere ao consumo de batata no segundo período analisado neste trabalho, compreendendo de julho de 2018 a outubro de 2018. Neste gráfico apresenta-se o consumo previsto, a meta, o total entregue e o quantitativo de perdas de batatas fritas tipo chips (em toneladas) no segundo período. Pode-se destacar que neste período a produção efetiva de batatas em alguns meses ficou aproximada a meta estabelecida e em outros meses, atingiu a meta, além de, quando comparados ao primeiro período, houve uma redução no quantitativo de perdas de batatas. 
Figura 4 - consumos no segundo período.

CONSUMOS DE BATATAS - JUL./18 a OUT./18

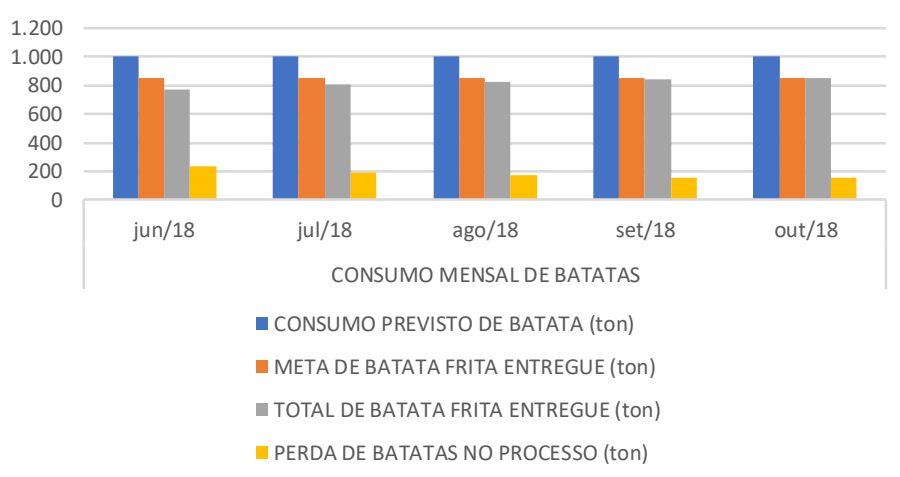

Fonte: Autores, (2018).

De acordo com a tabela 2, a Figura 5 apresenta um comparativo entre as metas de rendimento estabelecidos pela alta administração da empresa e o rendimento efetivamente alcançado no segundo período. É possível notar neste gráfico que durante o levantamento de dados coletados no segundo período de análise, o rendimento do processo que ocorreu ao longo dos meses apresentou um comportamento segundo uma tendência crescente, até o último mês de análise que foi possível observar o cumprimento da meta estabelecida.

Figura 5 - comparativo de rendimentos.

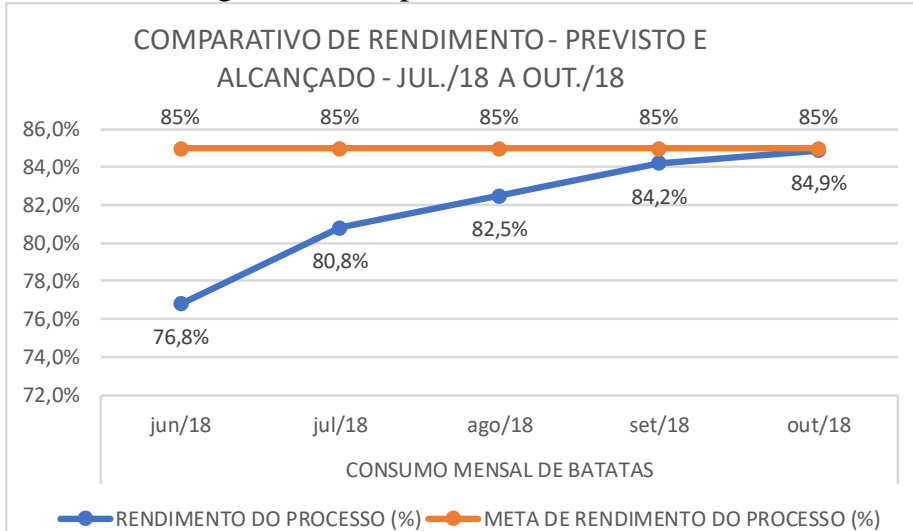

Fonte: Autores, (2018).

Com isso, foi possível observar com a análise dos resultados apresentados no segundo período, que as perdas de matéria prima foram reduzidas, e a performance e rendimento da linha estão de acordo com as metas estabelecidas pela alta direção.

A linha de produção que apresentava perdas consideráveis durante todo o processo, e com a implementação do plano de ação e identificação dos problemas apresentados reduziu as perdas de matéria prima e o objetivos e resultados foram alcançados pela empresa.

\section{CONSIDERAÇÕES FINAIS}

Em uma empresa é necessário que todos os seus setores trabalhem de forma integrada, buscando o mesmo objetivo estratégico, para que seja possível, entregar um produto de qualidade ao consumidor final, evitar desperdícios no processo produtivo, minimizando perdas e consequentemente aumentando a lucratividade da empresa.

Por meio do plano de melhoria proposto para a empresa, foi possível aplicar as propostas na realidade da fábrica, tais como: Controle de recebimento da carga de batatas, aquisição de equipamento para corte automático de batatas, e ajustes nas máquinas do empacotamento. Todas essas ações foram executadas no prazo previsto pelo plano de ação.

Com a implantação do plano de melhorias proposto, foi possível obter um aumento de rendimento do processo produtivo de batatas, que antes era de em média $68,1 \%$, para $81,8 \%$. Bem como foi possível observar a redução no nível de perdas de batatas do tipo chips, contribuindo para ao final do segundo período analisado, o alcance da meta estabelecida pela alta direção.

Com isso foi possível observar que quando se utiliza de forma correta os controles, as análises dos dados, e a aplicação da ferramenta de qualidade é possível obter processos produtivos mais eficazes, reduzindo as perdas de matéria-prima, mão-de- obra, e energia.

Como principal aprendizado da realização desse trabalho, foi observado que foi possível obter os objetivos dentro de uma organização com envolvimento de todas as áreas da organização.

\section{REFERENCIAS}

[1] Fogliatto, Flavio Sanson; Ribeiro, José Luis Duarte. Confiabilidade e manutenção industrial. Rio de Janeiro: Elsevier, 2009.

[2] Hansen, Robert C. Eficiência Global dos Equipamentos: uma poderosa ferramenta de produção/manutenção para o aumento dos lucros. Porto Alegre: Bookman, 2006.

[3] Santos, Carlos Aparecido. Produção enxuta: uma proposta de método para introdução em uma empresa multinacional instalado no Brasil. Disponível em: http://www.pgmec.utfpr.br/dissertações/dissertação 008.PDF. acesso em 03 de setembro 2018.

[4] Sharma, Anand; Moody, Patricia E.; Rosa, Maria Lucia G. Leite. A máquina perfeita: como vencer na nova economia produzindo com menos recursos. São Paulo: Prentice Hall, 2003.

[5] Paladini, E.P. Gestão da qualidade: a nova dimensão da gerência de produção. Trabalho apresentado à UFSC como parte dos requisitos de concurso de professor titular na área de gerência de produção. 1996.

[6] Toledo, J. C. Gestão da Qualidade na agroindústria. In: BATALHA, M.O. (org.). Gestão Agroindustrial. 2 ed. São Paulo: Atlas, 2001.

[7] Toledo, J. C.; Carpinetti, L. C. R. Gestão da Qualidade na Fábrica do Futuro. In: Rozenfeld, H. A Fábrica do Futuro. São Paulo: Banas, 2000.

[8] Maiczuk, J.; Júnior, P. P. A. Aplicação de Ferramentas de Melhoria de Qualidade e Produtividade nos Processos Produtivos: Um Estudo de Caso. Qualit@s Revista Eletrônica. Paraíba, v. 14, n. 1, p. 1-14, 2013.

[9] Capiotto, G. M.; Lourenzani, W. L. Sistema de Gestão de Qualidade na Indústria de Alimentos: Caracterização da Norma ABNT NBR ISO 22.000:2006. In: SOBER - Sociedade Brasileira de Economia Administração e Sociologia Rural, Tupã - SP, 2010. Disponível em: <http://www.sober.org.br/palestra/15/713.pdf>. Acesso em: 28 out. 2018.

[10] Kauark, Fabiana; MANHÃES, Fernanda; MEDEIROS, Carlos Henrique. Metodologia da pesquisa, guia prático. Itabuna; Via Litterarum, 2010. 
[11] Gil, A, C. Como elaborar projeto de pesquisa, São Paulo: Atlas, 2010.

[12] de Luca, Marcelo Alexandre Siqueira. A gestão da qualidade em processos primários de serviço: uma proposta de ferramenta aplicada ao processamento com pessoas. 2007. $271 \mathrm{f}$. Dissertação (Mestrado em Engenharia de Produção e Sistemas) Pontifícia Universidade Católica do Paraná, Curitiba, 2007.

[13] Mendonça, M. M.. F.; José, B. S.; Costa, S. R. R. Estudo da gestão da qualidade aplicada na produção de alimentos. XXIV Encontro Nacional de Engenharia de Produção - Florianópolis, SC, Brasil, 03 a 05 de novembro de 2004, p. 1566-1572.

[14] Paladini, Edson Pacheco et al. Gestão da Qualidade: Teoria e Casos. $2^{\mathrm{a}}$ edição, 2012. Editora Elsevier.

[15] Ballestero-Alvarez, Maria Esmeralda. Gestão de qualidade, produção e operações. São Paulo: Atlas, 2010.

[16] Costa, M. L. Como imitar os japoneses e crescer. Florianópolis: EDEME, 1991.

[17] Reyes A. E. L. Implantação de um Sistema de Qualidade. São Paulo: USP, 2000. Disponível em http://www.esalq.usp.br/qualidade/pagexp1. Acesso em $13 \mathrm{de}$ novembro de 2018.

[18] Candido, Sandro. Solução de problemas com uso do PDA e das ferramentas da qualidade. Disponível em: http://sandrocan.wordpress.com/tag/diagrama-de-causa-efeito->.

Acesso em 18 de outubro 2018. 